\title{
The Influence of Oxide Thickness and Indium Amount on the Analog Parameters of $\ln _{x} \mathrm{Ga}_{1-x}$ As nTFETs
}

\author{
Caio C. M. Bordallo, João Antonio Martino, Senior Member, IEEE, \\ Paula G. D. Agopian, Senior Member, IEEE, Alireza Alian, Yves Mols, \\ Rita Rooyackers, Anne Vandooren, Anne S. Verhulst, Eddy Simoen, \\ Cor Claeys, Fellow, IEEE, and Nadine Collaert
}

\begin{abstract}
The basic analog parameters of three splits of $\ln _{x} \mathrm{Ga}_{1-x}$ As nTFETs are analyzed for the first time. The first two splits are $\ln _{0.53} \mathrm{Ga}_{0.47}$ As devices with a 3-nm $\mathrm{HfO}_{2} / 1-\mathrm{nm} \mathrm{Al}_{2} \mathrm{O}_{3}$ and a 2-nm $\mathrm{HfO}_{2} / 1-\mathrm{nm} \mathrm{Al} \mathrm{O}_{3}$, while the last one is an $\ln _{0.7} \mathrm{Ga}_{0.3}$ As channel with a 3-nm $\mathrm{HfO}_{2} / 1-\mathrm{nm}$ $\mathrm{Al}_{2} \mathrm{O}_{3}$ gate. The low equivalent oxide thickness improves the electrostatic coupling, enhancing IDS, and, consequently, also $\mathrm{gm}$ and $A_{V}$, especially for higher $V_{G S}$. The InGaAs tunnel field-effect transistors (TFETs) show compatible performance with Si TFETs, and have better performance than Si MOSFETs, making them useful for low-power and lowvoltage analog applications. The highest efficiency is found using the combination of a $2-\mathrm{nm} \mathrm{HfO}_{2}$ with $\ln _{0.53} \mathrm{Ga}_{0.47} \mathrm{As}$, due to the 56-mV/dec subthreshold swing obtained. For all splits, the $A_{V}$ peak can be related to the $V_{G S}$ necessary for band-to-band tunneling to become the dominant transport mechanism.
\end{abstract}

Index Terms-Analog parameters, current conduction mechanisms, intrinsic voltage gain, sub-60 mV/dec, tunnel field-effect transistors (TFET).

\section{INTRODUCTION}

$\mathbf{T}$ UNNEL field-effect transistors (TFETs) are a relatively new type of transistors that uses the band-to-band tunneling (BTBT), where its structure is a gated p-i-n diode [1]. The TFETs were designed for logic applications because of their

Manuscript received April 24, 2017; revised June 20, 2017; accepted June 22, 2017. Date of publication August 3, 2017; date of current version August 21, 2017. This work was supported in part by CNPq, in part by FAPESP, and in part by the Imec's Logic Device Program and its Core Partners. The review of this paper was arranged by Editor P. J. Fay. (Corresponding author: Caio C. M. Bordallo.)

C. C. M. Bordallo and J. A. Martino are with the University of São Paulo, São Paulo 05508-010, Brazil (e-mail: caiobordallo@gmail.com; martino@Isi.usp.br)

P. G. D. Agopian is with the University of São Paulo, São Paulo 05508010, Brazil, and also with São Paulo State University, São João da Boa Vista 13876-750, Brazil (e-mail: agopian@Isi.usp.br).

A. Alian, Y. Mols, R. Rooyackers, A. Vandooren, A. S. Verhulst, E. Simoen, and N. Collaert are with Imec, Leuven 3001, Belgium (e-mail: alireza.alian@imec.be; yves.mols@imec.be; rita.rooyackers@imec.be; anne.vandooren@imec.be; anne.verhulst@imec.be; eddy.simoen@ imec.be; nadine.collaert@imec.be).

C. Claeys is with Imec, Leuven 3001, Belgium, and also with the Electrical Engineering Department, KU Leuven, 3000 Leuven, Belgium (e-mail: claeys@imec.be).

Color versions of one or more of the figures in this paper are available online at http://ieeexplore.ieee.org.

Digital Object Identifier 10.1109/TED.2017.2721110 capability to overcome the theoretical limit of the subthreshold swing (SS) of conventional MOSFETs $(60 \mathrm{mV} / \mathrm{dec}$ at room temperature) [2]-[4], leading to a reduction of the power consumption. TFETs with sub- $60 \mathrm{mV} / \mathrm{dec}$ SS have already been demonstrated in [5].

However, Si TFETs present very low ON-state current $\left(I_{\mathrm{ON}}\right)$ due to its high bandgap $(1.1 \mathrm{eV})$. Different semiconductor materials with the lower bandgap can be used to increase $I_{\mathrm{ON}}$. Ge compounds [6]-[9] and III-V materials [10]-[14] are examples with the lower bandgap that can be used to obtain higher $I_{\mathrm{ON}}$. The TFET design proposed in [10] is a vertical $\mathrm{In}_{0.53} \mathrm{Ga}_{0.47}$ As device approach using the same material layer structure as for the horizontal devices studied in this paper.

Besides excellent potential for logic applications due to their improved switching characteristics ( $\mathrm{SS}<60 \mathrm{mV} / \mathrm{dec}$ ), TFETs are also promising for analog applications, as reported in [15]-[23], where in [20] and [22], a comparison between TFETs and MOSFETs has shown better analog performance of TFETs. Some basic analog circuits have also been studied, not only presenting promising characteristics but also limitations [24]-[27], showing that the differential and common mode gains for the TFET differential pair were around 1-2 higher times than that for FinFETs [25], with the TFET differential pairs being also less influenced by the temperature [26].

The focus of this paper is the study of the influence of the indium amount and the $\mathrm{HfO}_{2}$ thickness on the analog parameters of $\operatorname{In}_{x} \mathrm{Ga}_{1-x}$ As nTFETs with the $\mathrm{Zn}$ source diffusion from the gas phase. For these analyses, three different splits are considered, the first is $\mathrm{In}_{0.53} \mathrm{Ga}_{0.47}$ As with a $3 \mathrm{~nm}$ of $\mathrm{HfO}_{2}$, the second is $\operatorname{In}_{0.53} \mathrm{Ga}_{0.47} \mathrm{As}$ with a $2 \mathrm{~nm}$ of $\mathrm{HfO}_{2}$, and the last is $\mathrm{In}_{0.7} \mathrm{Ga}_{0.3}$ As with a $3 \mathrm{~nm}$ of $\mathrm{HfO}_{2}$.

\section{Device Characteristics}

The studied devices are n-type $\operatorname{In}_{x} \mathrm{Ga}_{1-x}$ As homojunction TFETs fabricated by using the $\mathrm{Zn}$ gas phase diffusion. The device follows the approach introduced by the University of Tokyo [11], [28], and further optimized in [29] using the solid-source diffusion and in [30] using the gas phase $\mathrm{Zn}$ diffusion. A schematic representation of the fabricated $\mathrm{In}_{x} \mathrm{Ga}_{1-x}$ As nTFETs is presented in Fig. 1. 


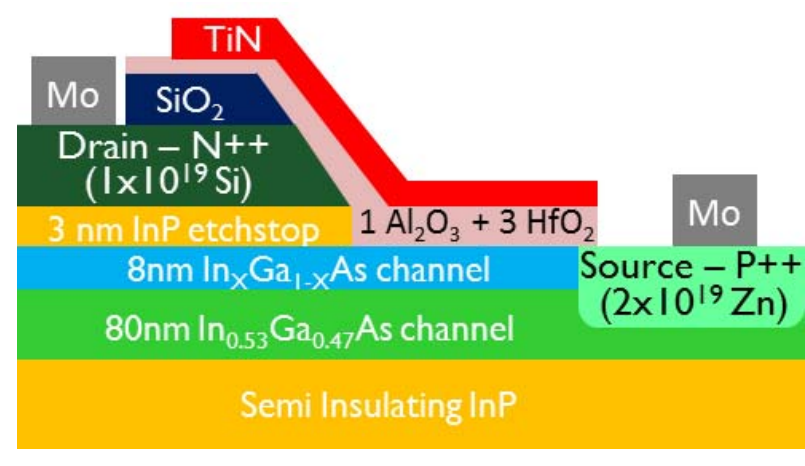

Fig. 1. Schematic representation of the $\ln _{X} G a_{1-X}$ As nTFET used.

Three different splits were analyzed, two splits with a uniform $\operatorname{In}_{0.53} \mathrm{Ga}_{0.47}$ As channel and the other one has an extra 8-nm $\operatorname{In}_{0.7} \mathrm{Ga}_{0.3}$ As layer on top of the $\operatorname{In}_{0.53} \mathrm{Ga}_{0.47}$ As channel, as can be observed in Fig. 1. The $\operatorname{In}_{0.7} \mathrm{Ga}_{0.3} \mathrm{As}$ and one of the $\mathrm{In}_{0.53} \mathrm{Ga}_{0.47}$ As devices have a 3-nm $\mathrm{HfO}_{2}$ on the top of 1-nm $\mathrm{Al}_{2} \mathrm{O}_{3}$, resulting in an equivalent oxide thickness (EOT) of about $1 \mathrm{~nm}$. The last $\mathrm{In}_{0.53} \mathrm{Ga}_{0.47}$ As device has a 2-nm $\mathrm{HfO}_{2}$ on the top of a 1-nm $\mathrm{Al}_{2} \mathrm{O}_{3}$, resulting in an EOT of about $0.8 \mathrm{~nm}$. The gate-stack uses TiN as the metal gate. The drain is doped with $\mathrm{Si}(\mathrm{N}++)$, and the $\mathrm{P}++$ source is doped with $\mathrm{Zn}$ using the gas phase diffusion [30]. The width is about $400 \mu \mathrm{m}$ and the gate length is about $5 \mu \mathrm{m}$. More processing details can be found in [30].

\section{Analysis And Results}

Fig. 2 presents the drain current $\left(I_{\mathrm{DS}}\right)$ as a function of the gate voltage $\left(V_{\mathrm{GS}}\right)$ for the three different splits with the drain voltage $\left(V_{\mathrm{DS}}\right)$ biased at 0.6 and $1 \mathrm{~V}(\mathrm{~A})$, and biased at 0.05 and $0.2 \mathrm{~V}(\mathrm{~B})$. One can observe that $I_{\mathrm{ON}}$ is higher for the $\mathrm{In}_{0.7} \mathrm{Ga}_{0.3}$ As nTFET because of its lower bandgap $\left(E_{g}\right)$ $\left(E_{g}, \mathrm{In}_{0.53} \mathrm{Ga}_{0.47} \mathrm{As}=0.752 \mathrm{eV}\right.$ and $E_{g}, \mathrm{In}_{0.7} \mathrm{Ga}_{0.3} \mathrm{As}=$ $0.588 \mathrm{eV}$ [31]). Also, the reduction of the onset voltage $\left(V_{\mathrm{ON}}\right)$ contributes to the increase of $I_{\mathrm{ON}}$. Considering the effect of the reduction of the EOT, from 3 to $2 \mathrm{~nm}$ of $\mathrm{HfO}_{2}$ in the $\mathrm{In}_{0.53} \mathrm{Ga}_{0.47}$ As split, the $I_{\mathrm{ON}}$ increases slightly due to the better electrostatic control, improving also the subthreshold characteristics, reaching sub-60 mV/dec values. In Fig. 2, it is also possible to observe that $I_{\mathrm{DS}}$ enhances when $V_{\mathrm{GS}}$ increases. This enhancement is caused by the reduction of the tunneling length, which raises the BTBT generation rate, resulting in an increase of $I_{\mathrm{DS}}$. Not only the $I_{\mathrm{DS}}$ is increased when enhancing the BTBT generation but also the hysteresis is improved (reduced), being lower for the $\mathrm{In}_{0.7} \mathrm{Ga}_{0.3} \mathrm{As}$ device with high $I_{\mathrm{DS}}$ resulting in the hysteresis of $14 \mathrm{mV}$. The $\mathrm{In}_{0.53} \mathrm{Ga}_{0.47}$ As device with a $2 \mathrm{~nm}$ of $\mathrm{HfO}_{2}$ is the second best $(16 \mathrm{mV})$. The $\operatorname{In}_{0.53} \mathrm{Ga}_{0.47}$ As device with a $3 \mathrm{~nm}$ $\mathrm{HfO}_{2}$ is less influenced by BTBT and presents the highest hysteresis $(25 \mathrm{mV})$.

The transconductance $(\mathrm{gm})$, which is given in Fig. 3, presents the same tendency as $I_{\mathrm{DS}}$, showing the higher gm for the $\mathrm{In}_{0.7} \mathrm{Ga}_{0.3} \mathrm{As}$, the lower gm for the $\mathrm{In}_{0.53} \mathrm{Ga}_{0.47}$ As channel with a $2 \mathrm{~nm}$ of $\mathrm{HfO}_{2}$, and also an increase with $V_{\mathrm{GS}}$.

Fig. 4 presents the output conductance $\left(g_{D}\right)$ as a function of $V_{\mathrm{GS}}$ for all the three analyzed splits. As $V_{\mathrm{GS}}$ becomes higher,
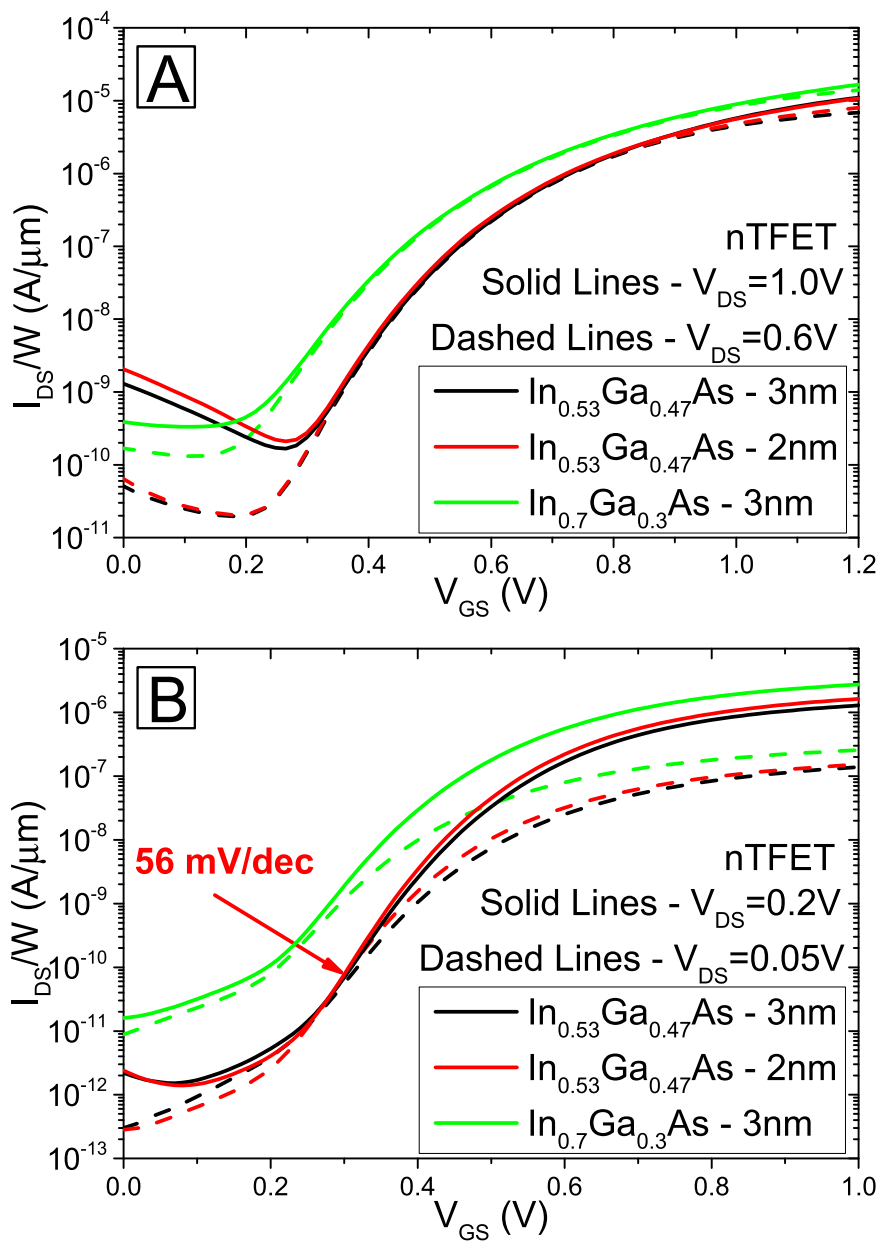

Fig. 2. Experimentally normalized $I_{D S}$ as a function of $V_{\mathrm{GS}}$ for $\mathrm{In}_{0.7} \mathrm{Ga}_{0.3}$ As and $\operatorname{In}_{0.53} \mathrm{Ga}_{0.47}$ As (both EOTs) nTFETs. (A) With $V_{\mathrm{DS}}$ of 0.6 and $1 \mathrm{~V}$. (B) With $V_{\mathrm{DS}}$ of 0.05 and $0.2 \mathrm{~V}$.

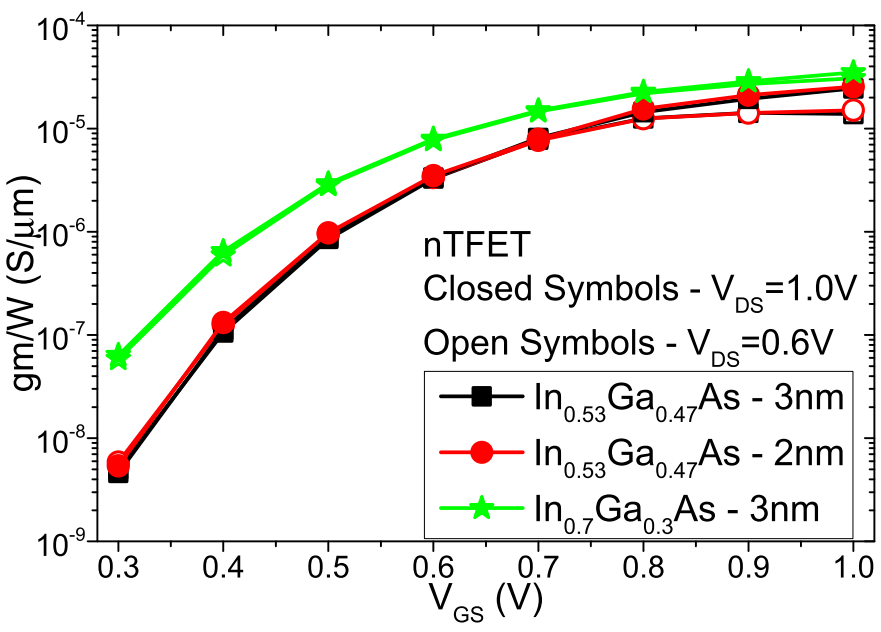

Fig. 3. Experimentally normalized gm as a function of $V_{\mathrm{GS}}$ for $\ln _{0.7} \mathrm{Ga}_{0.3}$ As and $\ln _{0.53} \mathrm{Ga}_{0.47}$ As (both EOTs) nTFETs, with $V_{\mathrm{DS}}$ of 0.6 and $1 \mathrm{~V}$.

$g_{D}$ increases (degrades) due to the higher $V_{\mathrm{DS}}$ dependence of the effective energy window of overlap at the source-channel junction for higher $V_{\mathrm{GS}}$ [32]. This energy window, where BTBT occurs, is the region limited by the valence band of the source, the conduction band of the channel and the drain, and also the Fermi levels. As $V_{\mathrm{DS}}$ is increased, this energy 


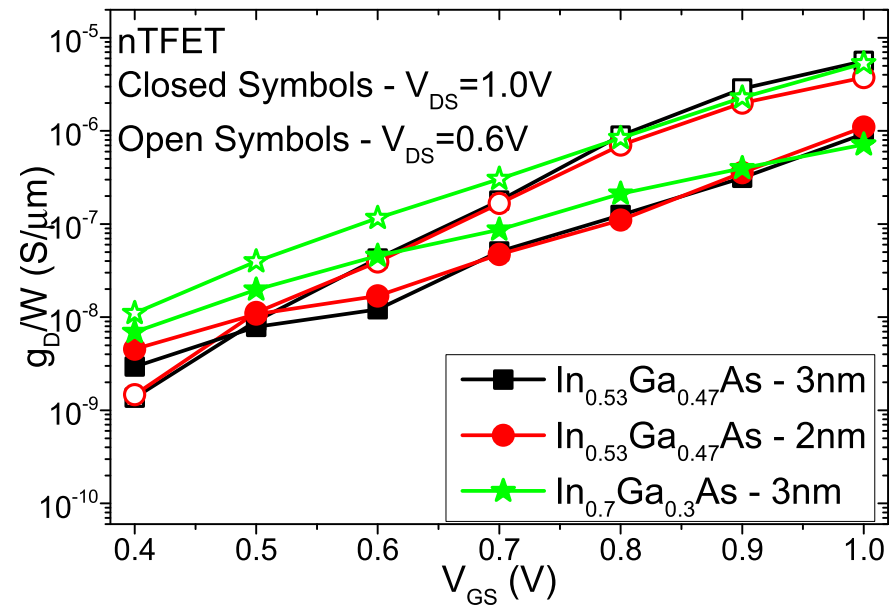

Fig. 4. Experimentally normalized $g_{D}$ as a function of $V_{\mathrm{GS}}$ for $\mathrm{In}_{0.7} \mathrm{Ga}_{0.3}$ As and $\ln _{0.53} \mathrm{Ga}_{0.47}$ As (both EOTs) nTFETs, with $V_{\mathrm{DS}}$ of 0.6 and $1 \mathrm{~V}$.

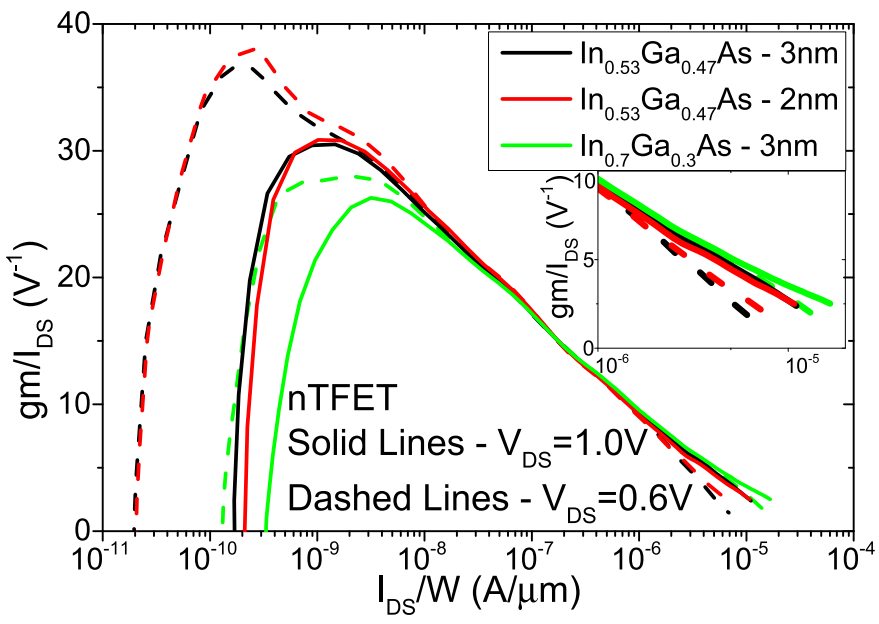

Fig. 5. Experimental $\mathrm{gm} / \mathrm{I}_{\mathrm{DS}}$ as a function of normalized $I_{\mathrm{DS}}$ for $\ln _{0.7} \mathrm{Ga}_{0.3}$ As and $\ln _{0.53} \mathrm{Ga}_{0.47}$ As (both EOTs) nTFETs, with $V_{\mathrm{DS}}$ of 0.6 and $1 \mathrm{~V}$.

window becomes wider, reducing the influence of the drain and improving (decreasing) $g_{D}$. This improvement can also be observed in the $I_{\mathrm{DS}}$ and gm curves, where for high $V_{\mathrm{GS}}$, both quantities increase with $V_{\mathrm{DS}}$. Analyzing the influence of the percentage of indium, it is possible to observe different behaviors for the splits. The $\mathrm{In}_{0.7} \mathrm{Ga}_{0.3}$ As split presents higher $g_{D}$ values than the $\operatorname{In}_{0.53} \mathrm{Ga}_{0.47}$ As splits at low $V_{\mathrm{GS}}\left(V_{\mathrm{GS}} \approx\right.$ $0.5 \mathrm{~V}$ ); however, for high $V_{\mathrm{GS}}$ values, they present similar values.

Another important figure of merit for the analog performance is the transistor efficiency $\left(\mathrm{gm} / I_{\mathrm{DS}}\right)$, where it is possible to study the transistor performance from weak to strong conduction regime (Fig. 5). In the strong conduction regime, the dominant parameter is the gm. In this regime, all the samples present similar behavior at $V_{\mathrm{DS}}=1 \mathrm{~V}$, due to their similar $\mathrm{gm}$ at the same $I_{\mathrm{DS}}$. However, at $V_{\mathrm{DS}}=0.6 \mathrm{~V}$, the $\mathrm{In}_{0.7} \mathrm{Ga}_{0.3}$ As presented a slightly better efficiency compared with $\mathrm{In}_{0.53} \mathrm{Ga}_{0.47}$ As samples.

In the weak conduction regime (peak region), the efficiency is inversely related to the SS of the devices. The SS as a

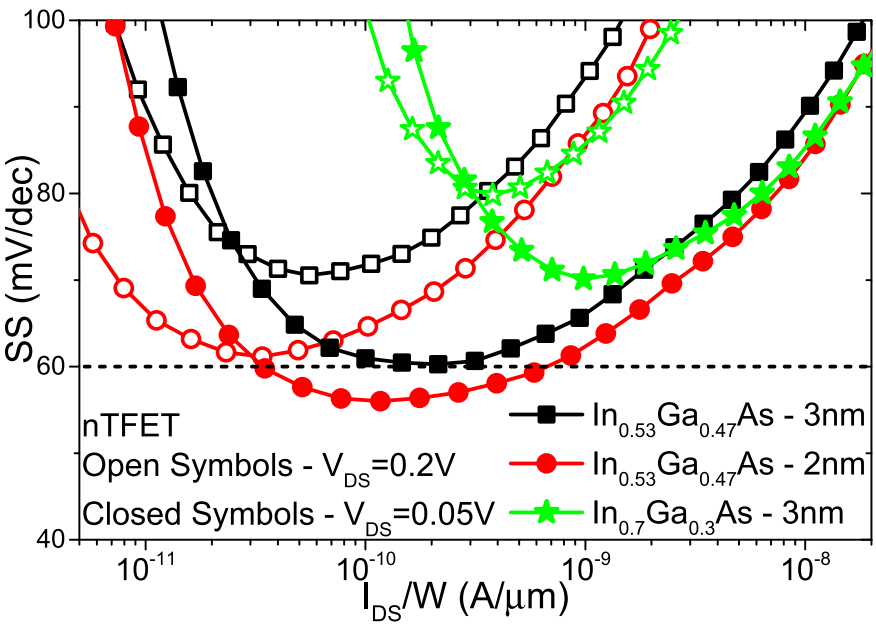

Fig. 6. Experimental SS as a function of normalized $I_{\mathrm{DS}}$ for $\ln _{0.7} \mathrm{Ga}_{0.3} \mathrm{As}$ and $\ln _{0.53} \mathrm{Ga}_{0.47}$ As (both EOTs) nTFETs, with $V_{\mathrm{DS}}$ of 0.05 and $0.2 \mathrm{~V}$.

function of the normalized $I_{\mathrm{DS}}$ is presented in Fig. 6. In the efficiency curve, at weak conduction regime, it is noticeable that the $\mathrm{In}_{0.53} \mathrm{Ga}_{0.47}$ As with a $2 \mathrm{~nm}$ of $\mathrm{HfO}_{2}$ yields the best efficiency. This high efficiency is related to its sub- $60 \mathrm{mV} / \mathrm{dec}$ behavior, as shown in Fig. 6, where the $\mathrm{In}_{0.53} \mathrm{Ga}_{0.47}$ As presents the best efficiency characteristics at weak conduction regime. Although the $\operatorname{In}_{0.7} \mathrm{Ga}_{0.3}$ As sample demonstrates satisfactory results at the strong conduction regime, at the weak conduction regime, it exhibits a degraded efficiency, worse than both $\mathrm{In}_{0.53} \mathrm{Ga}_{0.47} \mathrm{As}$ samples. This degradation is related to its high OFF-state current $\left(I_{\mathrm{OFF}}\right)$, as can be observed in Fig. 2(B), showing $I_{\mathrm{DS}}$ for the low $V_{\mathrm{DS}}$ polarization.

Fig. 7 presents the $I_{\mathrm{DS}}$ as a function of $V_{\mathrm{DS}}$, presenting the output characteristics of the studied devices. The early voltage $\left(V_{\mathrm{EA}}\right)$ is another important analog parameter that relates the output characteristics with the drain current (Fig. 8). The $V_{\mathrm{EA}}$ can be extracted by the intercept value with the $V_{\mathrm{DS}}$ axis $\left(I_{\mathrm{DS}}=0\right)$ obtained by a linear extrapolation of the $I_{\mathrm{DS}}$ as a function of $V_{\mathrm{DS}}$.

One can observe that for $V_{\mathrm{DS}}=1 \mathrm{~V}, V_{\mathrm{EA}}$ presents higher values than for $V_{\mathrm{DS}}=0.6 \mathrm{~V}$, a behavior that is due to the higher $I_{\mathrm{DS}}$ current. Moreover, for higher $V_{\mathrm{DS}}$, the device operates more in a saturation-like region; that is, it has less drain dependence, resulting in a higher $V_{\mathrm{EA}}$.

For low $V_{\mathrm{GS}}, V_{\mathrm{EA}}$ is also low because it is dominated by the low $I_{\mathrm{DS}}$. As the $V_{\mathrm{GS}}$ is increased, the current is enhanced, causing an improvement in $V_{\mathrm{EA}}$. However, increasing even more $V_{\mathrm{GS}}$, besides increasing $I_{\mathrm{DS}}$, the drain dependence also increases ( $g_{D}$ degradation), resulting in a reduction of $V_{\mathrm{EA}}$ for high $V_{\mathrm{GS}}$ values.

The $\operatorname{In}_{0.7} \mathrm{Ga}_{0.3}$ As device presents higher $V_{\mathrm{EA}}$ due to its higher $I_{\mathrm{DS}}$ and $g_{D}$, especially for low $V_{\mathrm{GS}}$ and $V_{\mathrm{DS}}$ above $0.8 \mathrm{~V}$. At low $V_{\mathrm{GS}}$ bias, the output characteristic presents an anomalous behavior in the saturation-like region, as can be observed in Fig. 7. In this case, for high drain bias, the TFET works like a diode, tunneling at the channel or drain junction, increasing the drain influence in $I_{\mathrm{DS}}$, and resulting in a degradation of $V_{\text {EA }}$. The $\operatorname{In}_{0.53} \mathrm{Ga}_{0.47}$ As device is more 

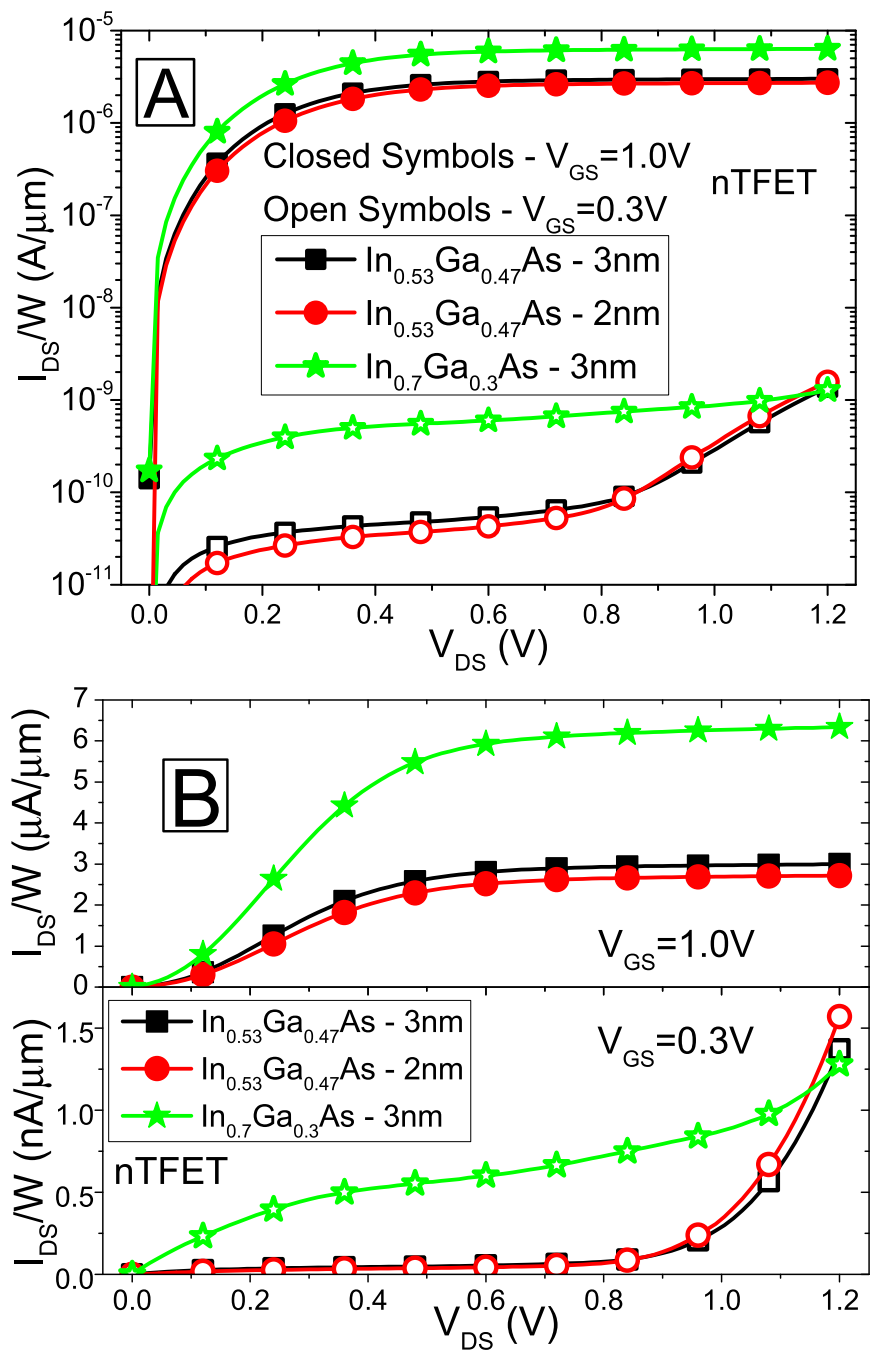

Fig. 7. Experimentally normalized $I_{\mathrm{DS}}$ as a function of $V_{\mathrm{DS}}$ for $\ln _{0.7} \mathrm{Ga}_{0.3}$ As and $\ln _{0.53} \mathrm{Ga}_{0.47}$ As (both EOTs) nTFETs, with $V_{\mathrm{GS}}$ of 0.3 and $1 \mathrm{~V}$ in $(\mathrm{A})$ logarithmic and (B) linear scales.

susceptible to this diode behavior than the $\operatorname{In}_{0.7} \mathrm{Ga}_{0.3}$ As device due to the lower $V_{\mathrm{ON}}$ of the last one.

One of the most important figures of merit for analog performance is the intrinsic voltage gain $\left(A_{V}\right)$, shown in Fig. 9. This parameter can be calculated by the gm and $g_{D}$ ratio, or using $V_{\mathrm{EA}}$ and the transistor efficiency, as can be seen in the following:

$$
A_{V}=20 \cdot \log \left(\left|\frac{\mathrm{gm}}{g_{D}}\right|\right)=20 \cdot \log \left(V_{\mathrm{EA}} \cdot \frac{\mathrm{gm}}{I_{\mathrm{DS}}}\right) .
$$

One can observe that there are two different behaviors of the samples, depending on the $V_{\mathrm{GS}}$ applied. For low $V_{\mathrm{GS}}$, the $\operatorname{In}_{0.7} \mathrm{Ga}_{0.3}$ As is the poorest performing device at $V_{\mathrm{DS}}=$ $0.6 \mathrm{~V}$, due to its high $I_{\mathrm{OFF}}$, which degrades the efficiency and $g_{D}$. However, at $V_{\mathrm{DS}}=1 \mathrm{~V}$, it presents $A_{V}$ values better than the $\mathrm{In}_{0.53} \mathrm{Ga}_{0.47}$ As samples due to the more pronounced diode behavior of the $\operatorname{In}_{0.53} \mathrm{Ga}_{0.47} \mathrm{As}$ device at this bias.

For high $V_{\mathrm{GS}}$, it is noticeable that the $\operatorname{In}_{0.7} \mathrm{Ga}_{0.3}$ As device has better $A_{V}$ than the $\operatorname{In}_{0.53} \mathrm{Ga}_{0.47}$ As case, due to its better gm and $V_{\mathrm{EA}}$, independent of the $V_{\mathrm{DS}}$ applied. Comparing the EOT scaling in the $\mathrm{In}_{0.53} \mathrm{Ga}_{0.47}$ As nTFET at high $V_{\mathrm{GS}}$ bias,

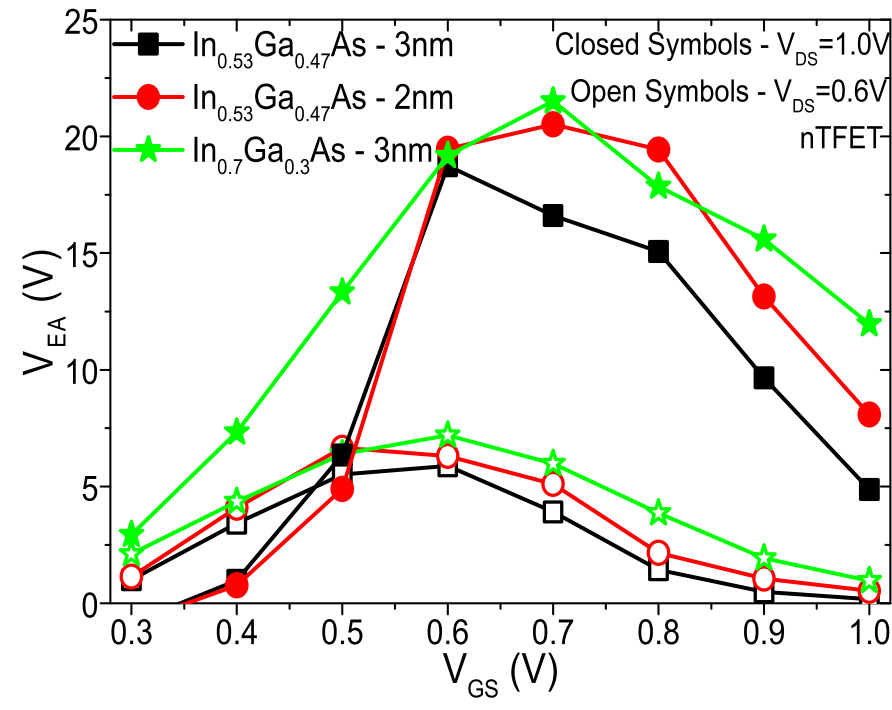

Fig. 8. Experimental $V_{\mathrm{EA}}$ as a function of $V_{\mathrm{GS}}$ for $\ln _{0.7} \mathrm{Ga}_{0.3} \mathrm{As}$ and $\mathrm{In}_{0.53} \mathrm{Ga}_{0.47}$ As (both EOTs) nTFETs, with $V_{\mathrm{DS}}$ of 0.6 and $1 \mathrm{~V}$.

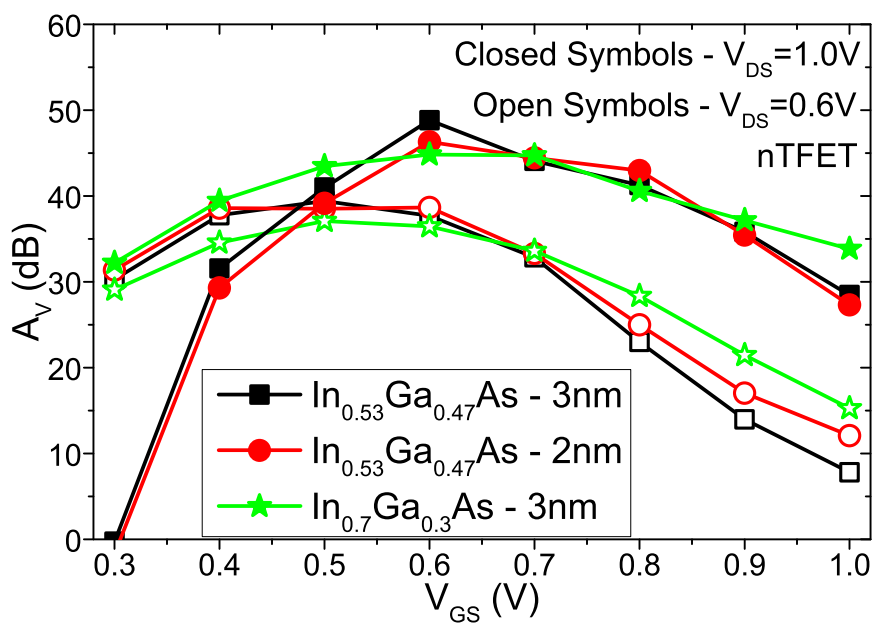

Fig. 9. Experimental $A_{V}$ as a function of $V_{\mathrm{GS}}$ for $\ln _{0.7} \mathrm{Ga}_{0.3} \mathrm{As}$ and $\mathrm{In}_{0.53} \mathrm{Ga}_{0.47}$ As (both EOTs) nTFETs, with $V_{\mathrm{DS}}$ of 0.6 and $1 \mathrm{~V}$.

it can be observed that the $2 \mathrm{~nm} \mathrm{HfO}_{2}$ device presents better $A_{V}$ values for $V_{\mathrm{DS}}=0.6 \mathrm{~V}$, due to its better electrostatic coupling.

For $V_{\mathrm{GS}}$ higher than $0.4 \mathrm{~V}$, where the diode behavior is suppressed, one important characteristic that can be observed is the peak presented in the $A_{V}$ curve of all the samples. This $A_{V}$ peak can be related with the conduction mechanism of the drain current, and it can be investigated by using the activation energy $\left(E_{a}\right)$, presented in Fig. 10 . The $E_{a}$ is obtained using temperature-dependent measurements, using the Arrhenius plot [23]. When the BTBT starts to dominate the transport, where $A_{V}$ starts to become more constant, gm has its maximum increase rate. Beyond that onset point the gm increase rate becomes lower (Fig. 3). While gm presents this behavior, $g_{D}$ continues to increase in a more linear progression with the increasing $V_{\mathrm{GS}}$, and when $g_{D}$ starts to increase more than gm, $A_{V}$ starts to degrade, which in turns results in this peak in the $A_{V}$ curve. 

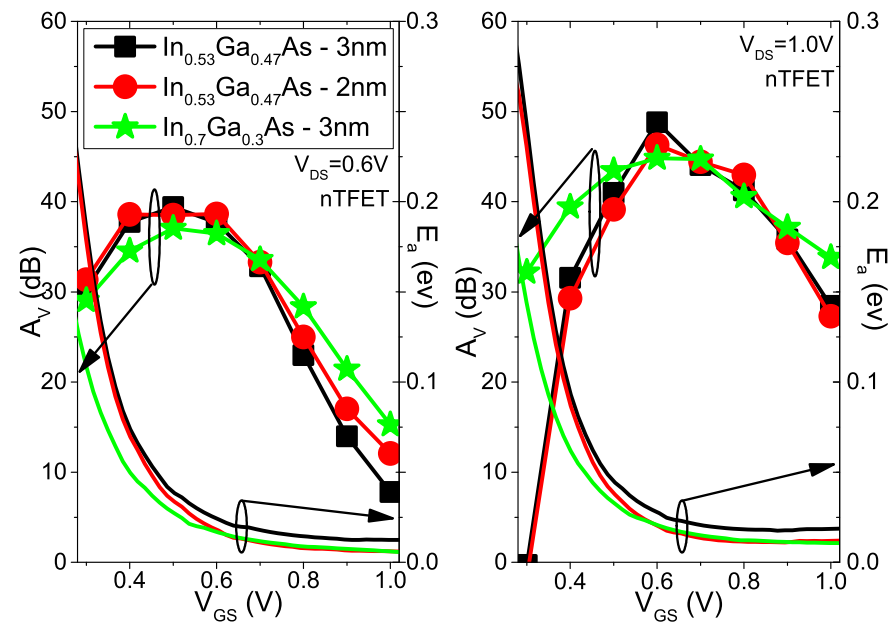

Fig. 10. Experimental $A_{V}$ and $E_{\mathrm{a}}$ as a function of $V_{\mathrm{GS}}$ for $\ln _{0.7} \mathrm{Ga}_{0.3} A s$ and $\mathrm{In}_{0.53} \mathrm{Ga}_{0.47}$ As (both EOTs) nTFETs, with $V_{\mathrm{DS}}$ of 0.6 and $1 \mathrm{~V}$.

The $A_{V} \mathrm{~s}$ presented in Fig. 9 are compatible to Si NW-TFETs and better than the Si NW-MOSFETs reported in [22], showing good analog characteristics.

\section{CONCLUSION}

In this paper, the analysis of the basic analog parameters is done for three different splits, i.e., $\operatorname{In}_{0.53} \mathrm{Ga}_{0.47} \mathrm{As}$ with a $3 \mathrm{~nm}$ of $\mathrm{HfO}_{2}, \mathrm{In}_{0.53} \mathrm{Ga}_{0.47}$ As with a $2 \mathrm{~nm}$ of $\mathrm{HfO}_{2}$, and $\mathrm{In}_{0.7} \mathrm{Ga}_{0.3} \mathrm{As}$ with a $3 \mathrm{~nm}$ of $\mathrm{HfO}_{2}$. In the $\mathrm{In}_{0.7} \mathrm{Ga}_{0.3} \mathrm{As}$ device, the bandgap is lower causing an improvement of the BTBT current and consequently enhancing $I_{\mathrm{ON}}$. In this device, the $V_{\mathrm{ON}}$ is also lower, which improves $I_{\mathrm{ON}}$ even more. Although this lower bandgap promotes an increase of gm, it also degrades $g_{D}$, especially for low $V_{\mathrm{GS}}$ bias. A competition between these factors, gm improvement and $g_{D}$ degradation, results in better $A_{V}$ for $\operatorname{In}_{0.53} \mathrm{Ga}_{0.47}$ As at low $V_{\mathrm{GS}}$ and in better $A_{V}$ for $\operatorname{In}_{0.7} \mathrm{Ga}_{0.3}$ As at high $V_{\mathrm{GS}}$.

The use of a thinner EOT with the $\operatorname{In}_{0.53} \mathrm{Ga}_{0.47}$ As channel causes an improvement of the electrostatic coupling, enhancing $I_{\mathrm{DS}}$, and consequently improving gm and $A_{V}$, especially for higher $V_{\mathrm{GS}}$. The $A_{V}$ of the samples is compatible to Si NW-TFETs and better than Si NW-MOSFETs presented in [22], but for lower $V_{\mathrm{DS}}$ and $V_{\mathrm{GS}}$ biases, proving itself to be useful for analog applications at low power and low voltage.

Although the $\operatorname{In}_{0.7} \mathrm{Ga}_{0.3}$ As device presents a slightly higher efficiency for the strong current conduction regime, the $\mathrm{In}_{0.53} \mathrm{Ga}_{0.47} \mathrm{As}$ exhibits much better efficiency for the weak conduction regime. The $\operatorname{In}_{0.53} \mathrm{Ga}_{0.47}$ As nTFET with a $2 \mathrm{~nm}$ of $\mathrm{HfO}_{2}$ reveals the highest efficiency at weak conduction due to its $\mathrm{SS}$, which reaches a minimum value of $56 \mathrm{mV} / \mathrm{dec}$.

The $A_{V}$ peak found in all the samples can be related to the $V_{\mathrm{GS}}$ corresponding with the onset of BTBT as the dominant transport mechanism. Near this $V_{\mathrm{GS}}$ bias, the gm enhancement is the highest and this enhancement starts to decay beyond the onset point. When the gm increase rate starts to become smaller than the $g_{D}$ increase rate, which is more constant with $V_{\mathrm{GS}}$ increase, it results in a degradation of $A_{V}$, reducing its value for higher $V_{\mathrm{GS}}$.

\section{REFERENCES}

[1] W. M. Reddick and G. A. J. Amaratunga, "Silicon surface tunnel transistor," Appl. Phys. Lett., vol. 67, no. 4, pp. 494-496, Jul. 1995.
[2] W. Y. Choi, B.-G. Park, J. D. Lee, and T.-J. K. Liu, "Tunneling field-effect transistors (TFETs) with subthreshold swing (SS) less than 60 mV/dec," IEEE Electron Device Lett., vol. 28, no. 8, pp. 743-745, Aug. 2007.

[3] T. Krishnamohan, D. Kim, S. Raghunathan, and K. Saraswat, "Doublegate strained-ge heterostructure tunneling FET (TFET) with record high drive currents and $\ll 60 \mathrm{mV} / \mathrm{dec}$ subthreshold slope," in IEDM Tech. Dig., Dec. 2008, pp. 947-949.

[4] M. Kim, Y. Wakabayashi, R. Nakane, M. Yokoyama, M. Takenaka, and S. Takagi, "High $\mathrm{I}_{o n} / \mathrm{I}_{\text {off }}$ Ge-source ultrathin body strained-SOI tunnel FETs," in IEDM Tech. Dig., Dec. 2014, pp. 331-334.

[5] H. Lu and A. Seabaugh, "Tunnel field-effect transistors: State-of-theart," IEEE J. Electron Device Soc., vol. 2, no. 4, pp. 44-49, Jul. 2014.

[6] A. S. Verhulst, W. G. Vandenberghe, K. Maex, and G. Groeseneken, "Boosting the on-current of a $n$-channel nanowire tunnel field-effect transistor by source material optimization," J. Appl. Phys., vol. 104, no. 6, p. 064514, Sep. 2008.

[7] D. Leonelli, A. Vandooren, R. Rooyackers, S. De Gendt, M. M. Heyns, and G. Groeseneken, "Drive current enhancement in p-tunnel FETs by optimization of the process conditions," Solid-State Electron., vols. 65-66, pp. 28-32, Nov./Dec. 2011.

[8] A. Vandooren et al., "Analysis of trap-assisted tunneling in vertical Si homo-junction and SiGe hetero-junction tunnel-FETs," Solid-State Electron., vol. 83, pp. 50-55, May 2013.

[9] M. Schmidt et al., "Line and point tunneling in scaled $\mathrm{Si} / \mathrm{SiGe}$ heterostructure TFETs," IEEE Electron Device Lett., vol. 35, no. 7, pp. 699-701, Jul. 2014.

[10] S. Mookerjea, D. Mohata, T. Mayer, V. Narayanan, and S. Datta, "Temperature-dependent $I-V$ characteristics of a vertical $\mathrm{In}_{0.53} \mathrm{Ga}_{0.47}$ As tunnel FET,' IEEE Electron Device Lett., vol. 31, no. 6, pp. 564-566, Jun. 2010.

[11] S. Takagi, M.-S. Kim, M. Noguchi, K. Nishi, and M. Takenaka, "Tunneling FET device technologies using III-V and Ge materials," in Proc. Symp. Energy Efficient Electron. Syst. (E3S), Oct. 2015, pp. 1-2.

[12] D. Verreck et al., "Uniform strain in heterostructure tunnel field-effect transistors," IEEE Electron Device Lett., vol. 37, no. 3, pp. 337-340, Mar. 2016.

[13] E. Memisevic, J. Svensson, M. Hellenbrand, E. Lind, and L.-E. Wernersson, "Vertical InAs/GaAsSb/GaSb tunneling field-effect transistor on $\mathrm{Si}$ with $\mathrm{S}=48 \mathrm{mV} /$ decade and $\mathrm{I}_{o n}=10 \mu \mathrm{A} / \mu \mathrm{m}$ for $\mathrm{I}_{o f f}=1 \mathrm{nA} / \mu \mathrm{m}$ at $\mathrm{V}_{D S}=0.3 \mathrm{~V}$," in IEDM Tech. Dig., Dec. 2016, pp. 500-503.

[14] R. Pandey et al., "Performance benchmarking of p-type $\mathrm{In}_{0.65} \mathrm{Ga}_{0.35} \mathrm{As} / \mathrm{GaAs}_{0.4} \mathrm{Sb}_{0.6}$ and $\mathrm{Ge} / \mathrm{Ge}_{0.93} \mathrm{Sn}_{0.07}$ hetero-junction tunnel FETs," in IEDM Tech. Dig., Dec. 2016, pp. 521-523.

[15] A. Mallik and A. Chattopadhyay, "Tunnel field-effect transistors for analog/mixed-signal system-on-chip applications," IEEE Trans. Electron Devices, vol. 59, no. 4, pp. 888-894, Apr. 2012.

[16] P. G. D. Agopian, J. A. Martino, R. Rooyackers, A. Vandooren, E. Simoen, and C. Claeys, "Experimental comparison between trigate p-TFET and p-FinFET analog performance as a function of temperature," IEEE Trans. Electron Devices, vol. 60, no. 8, pp. 2493-2497, Aug. 2013.

[17] P. G. D. Agopian et al., "NW-TFET analog performance for different Ge source compositions," in Proc. IEEE SOI-3D-Subthreshold Microelectron. Technol. Unified Conf. (S3S), Oct. 2013, pp. 1-2.

[18] P. G. D. Agopian et al., "Influence of the source composition on the analog performance parameters of vertical nanowire-TFETs," IEEE Trans. Electron Devices, vol. 62, no. 1, pp. 16-22, Jan. 2015.

[19] Q.-T. Zhao et al., "Strained Si and SiGe nanowire tunnel FETs for logic and analog applications," IEEE J. Electron Device Soc., vol. 3, no. 3, pp. 103-114, May 2015.

[20] P. G. D. Agopian et al., "Intrinsic voltage gain of line-TFETs and comparison with other TFET and MOSFET architectures," in Proc. EuroSOI-ULIS, Jan. 2016, pp. 13-15.

[21] M. D. V. Martino et al., "Analog performance of vertical nanowire TFETs as a function of temperature and transport mechanism," SolidState Electron., vol. 112, pp. 51-55, Oct. 2015.

[22] P. G. D. Agopian et al., "Comparison between vertical silicon NW-TFET and NW-MOSFETfrom analog point of view," in Proc. EuroSOI-ULIS, Jan. 2015, pp. 233-236.

[23] C. C. M. Bordallo et al., "Impact of the NW-TFET diameter on the efficiency and the intrinsic voltage gain from a conduction regime perspective," IEEE Trans. Electron Devices, vol. 63, no. 7, pp. 2930-2935, Jul. 2016. 
[24] B. Sedighi, X. S. Hu, H. Liu, J. J. Nahas, and M. Niemier, "Analog circuit design using tunnel-FETs," IEEE Trans. Circuits Syst. I, Reg. Papers, vol. 62, no. 1, pp. 39-48, Jan. 2015.

[25] M. D. V. Martino, J. A. Martino, and P. G. D. Agopian, "Performance comparison between TFET and FinFET differential pair," in Proc. Symp. Microelectron. Technol. Devices (SBMicro), Aug./Sep. 2015, pp. 1-4.

[26] M. D. V. Martino, J. A. Martino, and P. G. D. Agopian, "Analysis of TFET and FinFET differential pairs with active load from $300 \mathrm{~K}$ to 450 K," in Proc. EuroSOI-ULIS, Jan. 2016, pp. 246-249.

[27] T. Mori et al., "Demonstrating performance improvement of complementary TFET circuits by ION enhancement based on isoelectronic trap technology," in IEDM Tech. Dig., Dec. 2016, pp. 512-515.

[28] M. Noguchi et al., "High $I_{\text {on }} / I_{\text {off }}$ and low subthreshold slope planartype InGaAs tunnel field effect transistors with $\mathrm{Zn}$-diffused source junctions," J. Appl. Phys., vol. 118, no. 4, p. 045712, 2015.

[29] A. Alian et al., "Record performance InGaAs homo-junction TFET with superior SS reliability over MOSFET," in IEDM Tech. Dig., Dec. 2015, pp. $823-826$.

[30] A. Alian et al., "InGaAs tunnel FET with sub-nanometer EOT and sub$60 \mathrm{mV} / \mathrm{dec}$ sub-threshold swing at room temperature," Appl. Phys. Lett., vol. 109, p. 243502, Dec. 2016.

[31] R. E. Nahory, M. A. Pollack, W. D. Johnson, and R. L. Barns, "Band gap versus composition and demonstration of Vegard's law for $\mathrm{In}_{1-X} \mathrm{Ga}_{X} \mathrm{As}_{Y} \mathrm{P}_{1-Y}$ lattice matched to InP," Appl. Phys. Lett., vol. 33, no. 7, pp. 659-661, Oct. 1978.

[32] A. S. Verhulst, D. Leonelli, R. Rooyackers, and G. Groeseneken, "Drain voltage dependent analytical model of tunnel field-effect transistors," J. Appl. Phys., vol. 110, p. 024510, Jul. 2011.

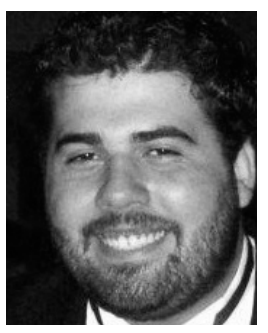

Caio C. M. Bordallo received the B.Eng. degree in electrical engineering and the M.Sc. degree from the Centro Universitário da FEI, São Bernardo do Campo, Brazil. He is currently pursuing the Ph.D. degree in microelectronics with the University of São Paulo, Paulo, Brazil.

Since 2014, he has been with the CMOS-SOI Research Group, University of São Paulo.

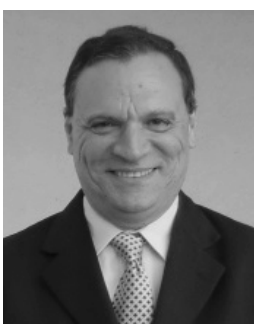

João Antonio Martino (M'06-SM'07) received the M.S. and Ph.D. degrees in microelectronics from the University of Sao Paulo (USP), São Paulo, Brazil.

He was a Post-Doctoral Researcher with Imec, Leuven, Belgium. Since 2005, he has been a Professor with USP and the Head of SOI Research Group since 1990.

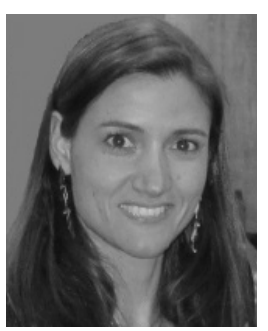

Paula G. D. Agopian (M'09-SM'15) received the M.S. and Ph.D. degrees in microelectronics from the University of Sao Paulo (USP), Sao Paulo, Brazil.

She is currently with LSI, USP, where she is involved in the field of tunnel field-effect transistors technology development.

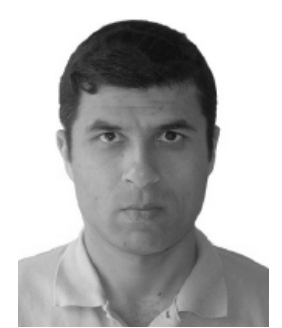

Alireza Alian received the bachelor's degree in electrical engineering from the University of Tehran, Tehran, Iran, in 2002, the master's degree from the Sharif University of Technology, Tehran, in 2004, and the Ph.D. degree from Katholieke Universiteit Leuven, Leuven, Belgium, in 2012.

$\mathrm{He}$ is currently with Imec, Leuven, where he is involved in III-V device research, MOSFET, and tunnel field-effect transistors devices.
Yves Mols received the M.S. degree in applied physics from Universiteit Gent, Ghent, Belgium, in 2001, and the Ph.D. degree in electrical engineering from Katholieke Universiteit Leuven, Leuven, Belgium, in 2008.

In 2001, he joined Imec, Leuven, Belgium, where he was with the Photovoltaics Department involved in the development of III-V solar cells for space and terrestrial applications. Since 2013, he has been involved in selective area growth of III-V on $300 \mathrm{~mm}$ Si for the beyond Silicon CMOS program with Imec.

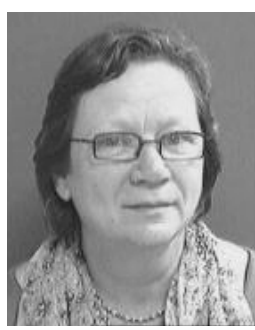

Rita Rooyackers received the B.Eng. degree in industrial chemistry from the Rega Institute, Katholieke Universiteit Leuven, Leuven, Belgium.

She is currently with Imec, Leuven, where she is involved in the field of tunnel field-effect transistors technology development.

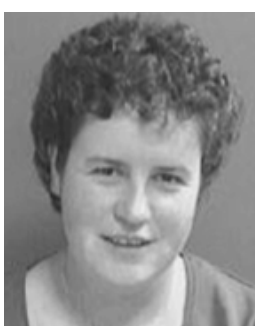

Anne Vandooren received the Ph.D. degree in electrical engineering from the University of California, Davis, CA, USA, in 2000.

She is currently a Senior Researcher with Imec, Leuven, Belgium, where she focuses on nanowire devices and tunneling-based transistors.

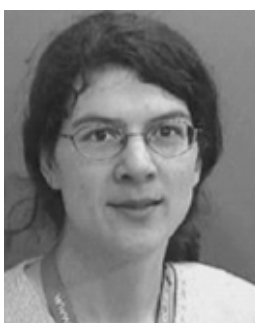

Anne S. Verhulst received the Ph.D. degree in electrical engineering from Stanford University, Stanford, CA, USA, in 2004

She is currently a Senior Researcher with Imec, Leuven, Belgium. She currently focuses on tunneling field-effect transistors.

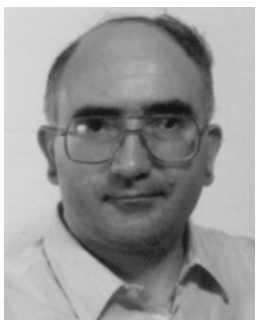

Eddy Simoen received the M.S. and Ph.D. degrees in engineering from Ghent University, Ghent, Belgium, in 1980 and 1985 , respectively.

Since 1986, he has been with Imec, Leuven, Belgium, where he is currently a Scientist.

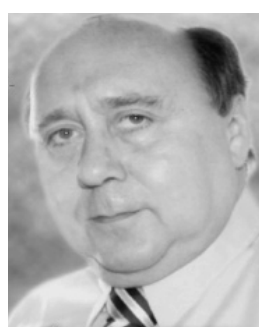

Cor Claeys (M'94-SM'95-F'09) received the Ph.D. degree from Katholieke Universiteit Leuven (KU Leuven), Leuven, Belgium.

Since 1984, he has been with Imec, Leuven. Since 1990, he has been a Professor with KU Leuven.

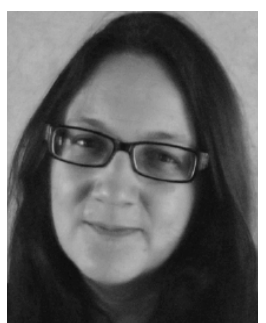

Nadine Collaert received the M.S. and Ph.D. degrees in electrical engineering from the Katholieke Universiteit Leuven, Leuven, Belgium, in 1995 and 2000, respectively.

Since 2012, she has been a Program Manager of the LOGIC Program with Imec, Leuven, where she is focusing on high-mobility channels, tunnel field-effect transistors, and nanowires. 